\title{
Changes in pupil size to visually presented words
}

JAMES M. POLT, Temple Buell College, and ECKHARD H. HESS, University of Chicago. Chicago, $\mathrm{Il}$.

The pupil response of 15 male and female $S s$ was recorded to four visually presented words. Sex differences were found in the pupil response, particularly in regard to response magnitude. Analysis of the individual response showed wide differences, from extreme dilation (34.5\%) to constriction (15.3\%) to a particular stimulus with a particular $S$.

The purpose of the present study was to: (1) determine the effects of variations in stimulus size on the pupil response and (2) to examine individual and sex differences in the response to words chosen to arouse some emotional response.

The question of the possiblity of deviations in response due to accommodation effects was discussed in an earlier paper dealing with mental problem solving (Hess \& Polt, 1964). While in that particular study the conclusion was reached that the results were not appreciably affected by accommodation, if it were an active factor, the question was not resolved as to possible response differences related to looking at stimuli of different size on the screen. The method of presenting the same stimulus, a word, in large and small letters was chosen to study possible size effects on the response.

The second aspect of the experiment was to examine the pupil response for both individual and sex differences. The possibility of the occurrence of these types of differences was suggested by unpublished data and the reports of Hess (1965), Hess, Seltzer, \& Shlien (1965), and Hess \& Polt (1960).

\section{SUBJECTS}

Nine men and six women served as Ss. All were students or assistants in the Department of Psychology at the University of Chicago, with a range in age from 24 to 45 years. All but two Ss had previously participated in pupillometric studies.

\section{APPARATUS}

The basic apparatus is a rectangular piece of equipment $24 \times 19$ $x$ 141/2 in. One end of the apparatus is equipped with a foam rubber face piece, and at the other end is a screen, $11 \times 11-1 / 4 \mathrm{in}$., for rear projection of stimuli. The image of the eye is reflected off a mirror into the lens of a Bolex $16 \mathrm{~mm}$ camera recording at the rate of 2 frames per sec on high speed infrared film. The apparatus is described in detail elsewhere (Hess \& Polt, 1966). Stimuli consisted of the four words: "hostile," "squirm," "flay," and "nude," projected in letters $3 / 4$ in. in height and in letters $1-1 / 2$ in. in height by means of a Bell and Howell $35 \mathrm{~mm}$ projector connected to a synchronous timer which advanced a slide every 10 sec. Before each stimulus slide was a control slide matched in brightness to the stimulus slide. This control slide consisted of the pattern of numbers 1 (upper left), 2 (upper tight), 3 (lower left), 4 (lower right), and 5 (center).

\section{PROCEDURE}

The $\mathbf{S}$ was seated at the apparatus, with the first control slide showing on the screen. He was told that he would be shown a series of slides, and that the first slide and every other slide in the series would be like the one on the screen. Each time he saw this slide he was to look at the numbers in order, then keep looking at the 5 until the slide changed. He was told to look at the other slides in any way he wanted to. The first time the numbers were alled off to give him the pace for looking at them.

Each $S$ saw each word twice. Once in large letters and once in small letters. Two orders of presentation were used. Group A had the order: hostile (small). squirm (large), flay (large), nude (small), squirm (small). flay (small), nude (large), hostile (large). For Group B, the stimuli were presented in the reverse order.

The processed film was measured frame-by-frame. The film was projected onto a rear projection screen set into a table top, which enlarged the image 17.5 times, and measurements of the pupil diameter were made with a millimeter ruler. All scores reflect the per cent difference in mean pupil size during the 20 frames the eye looked at a stimulus $(10 \mathrm{sec})$ with the mean of the pupil size during the previous $10 \mathrm{sec}$ control period.

$$
\text { RESULTS }
$$

An examination of the response to the words in large and small letters indicated that no significant difference existed (MannWhitney U-Test, Siegel, 1956). The mean response to the 60 large words ( $15 \mathrm{Ss} x$ four words) was $-.4 \%$. The mean response to the 60 small words was $+.1 \%$. On the first presentation only, the mean response to the large words was $+1.2 \%$ and to the small words $+.7 \%$. The mean responses on the second presentation was $-2.0 \%$ for the large words and $-.5 \%$ for the small words. While these means reflect the general downward response trend to the second viewing of the word (as seen in Table 1) again, there was no significant difference between the large and small words on either the first or second presentations. Lack of significance may have been due to the wide range of indivtdual differences in response. These results do indicate, however, that at least within the range of stimulus size used in the present study, it is unlikely that responses are influenced by the Ss trying to "see" the smaller words.

Table 1 shows the mean response to the four words for male and female Ss on both presentations. While there are distinct sex differences in responses, none of these proved to be significant at the .05 level (Mann-Whitney U-Test, Siegel, 1956). The word "flay" seemed to be particularly effective in arousing an emotional response in the male Ss the first time the word was seen. The same thing was true of "nude" although there was also considerable dilation from female Ss to this stimulus. The only word to which there was an increased response on the second presentation, as compared to the first, was the male response to the word "squirm." In two cases (male, "hostile"; female, "squirm") the response on the second presentation was essentially the same. In five cases there was a reduced response to the word on the second presentation.

The extreme range of individual responses can be seen in Table 2. As previously mentioned, these highly individual differences in response tended to "wash-out" any group differences to the four stimuli. In the male $S s$ the greatest range from the $S$ with the largest dilation to the $S$ with the largest constriction was to the word "flay" (45.7\%), although on an absolute basis the word "squirm" elicited the most constriction in an individual male S.

The female Ss did not equal the male in extreme dilation or constriction to any single stimulus.

Dilation and constriction responses were evenly divided among the 15 Ss for the first presentation with 30 responses in each direction ( $15 \mathrm{Ss}$ by four words). On the second presentation, the response breakdown was 38 constrictions and 22 dilations.

\section{DISCUSSION}

Previous pupillary research using words as stimuli has offered mixed results. Peavler \& McLaughlin (1967) presented nine nouns to Ss which had been previously rated on a "good-bad" and "neutral-very important" continuum prior to the recording of the pupil responses. They found neither a relationship between pupil responses and ratings nor a significant change in pupil sizes at any level. Pavio \& Simpson (1966) report dilation to word stimuli, with significantly greater dilation to abstract nouns than concrete nouns. While not primarily concerned with the pupil response to

Table 1

Mean Changes in Pupil Size to Four Words on Two Presentations. Changes are in Per Cent Plus or Minus from the Previous Control Period

\begin{tabular}{lccrcc}
\hline & \multicolumn{2}{c}{ Presentation 1 } & & \multicolumn{2}{c}{ Presentation 2 } \\
\cline { 2 - 3 } \cline { 6 - 6 } & Male & Female & & Male & Female \\
\hline hostile & -1.5 & +1.9 & & -1.4 & -4.1 \\
squirm & -2.0 & -1.5 & & +0.1 & -1.5 \\
flay & +4.7 & -0.2 & +0.8 & -2.0 \\
nude & +3.8 & +1.8 & 0.0 & -3.4 \\
\hline
\end{tabular}


Table 2

Range of Dilation and Constriction of Individual Male and Female Ss When First Presented with Four Words. Changes are in Per Cent Plus or Minus from the Previous Control Period

\begin{tabular}{llllll}
\hline & \multicolumn{2}{c}{ Male } & & \multicolumn{2}{c}{ Female } \\
\cline { 2 - 3 } \cline { 5 - 6 } & High & Low & & High & Low \\
\hline hostile & +8.0 & -12.3 & & +6.0 & -2.3 \\
squirm & +12.0 & -15.3 & & +7.7 & -8.0 \\
flay & +34.5 & -11.2 & & +14.2 & -6.3 \\
nude & +26.1 & -14.9 & & +14.6 & -5.3 \\
\hline
\end{tabular}

words per se, Hutt \& Anderson (1967) obtained dilation to words with various emotional connotations and related this to tachistoscopic recognition.

The present study presents further evidence that changes in pupil size do occur to visually presented words. However, emphasis has been on individual rather than group responses which reveals responses which are both dilative and constrictive in nature. Since both Peavler \& McLaughlin (1967) and Pavio \& Simpson (1966) combined $S$ and/or stimuli for purposes of analysis the individual response is obscured and there is no indication of what variations might occur from individual to individual.

As pointed out by Pavio \& Simpson (1966) any relationship between a word stimulus and dilation to the stimulus could be a function of mental activity, such as imagery, associated with the stimulus word. This could in part account for dilation in the present study, particularly to "flay" and "nude" which would be both rich and individualistic in imagery related arousal.

Constriction, as an individual phenomenon, could be related to perceptual vigilance, as suggested in the Hutt \& Anderson study (1967). If the nature of the arousal associated with the word is threatening, the reaction could well involve "shutting out" the stimulus via pupillary constriction.

While the constrictive phenomenon may continue to be a controversial aspect of pupillary research, the present data suggest that the constrictive response is highly individualistic, which would lead to difficulty in making generalizations as to what might constitute a "negative" stimulus.

\section{REFERENCES}

HESS, E. H. Attitude and pupil size. Scientific American, 1965, 212, 46.54. HESS, E. H., SELTZER, A. L., \& SHLIEN, J. M. Pupil response of heteroand homosexual males to pictures of men and women: A pilot study. Joumal of Abnormal Psychology, 1965, 70, 165-168.

HESS, E. H., \& POLT, J. M. Pupil size as related to interest value of visual stimuli. Science, $1960,132,349-350$.

HUTT, L. D., \& ANDERSON, J. P. The relationship between pupil size and recognition threshold. Psychonomic Science, 1967, 9, 477-478.

PAIVIO, A., \& SIMPSON, H. M. The effect of word abstractness and pleasantness on pupil size during an imagery task. Psychonomic Science, $1966,5,55.56$.

PEAVLER, W. S., \& McLAUGHLIN, J. P. The question of stimulus content and pupil size. Psychonomic Science, 1967, 8, 505-506.

SIEGEL, S. Non-parametric statistics. New York: McGraw-Hill, 1956. 